\title{
Patterned Metal/Polymer Strain Sensor with Good Flexibility, Mechanical Stability and Repeatability for Human Motion Detection
}

\author{
Xu Zheng, Qing Wang * ${ }^{\mathbb{D}}$, Jinjin Luan, Yao Li and Ning Wang \\ Institue of NanoEngineering, College of Civil Engineering and Architecture, Shandong University of Science and \\ Technology, Qingdao 266590, Shandong, China \\ * Correspondence: qwang@sdust.edu.cn
}

Received: 14 June 2019; Accepted: 12 July 2019; Published: 15 July 2019

\begin{abstract}
Wearable health monitoring smart systems based on flexible metal films are considered to be the next generation of devices for remote medical practice. However, cracks on the metallic surface of the films and difficulty in repeatability are the key issues that restrict the application of such wearable strain sensors. In this work, a flexible wearable strain sensor with high sensitivity and good repeatability was fabricated based on a patterned metal/polymer composite material fabricated through nanoimprint lithography. The mechanical properties were measured through cyclic tension and bending loading. The sensor exhibited a small $\Delta R / R_{0}$ error line for multiple test pieces, indicating the good mechanical stability and repeatability of the fabricated device. Moreover, the sensor possesses high sensitivity with gauge factors of 10 for strain less than $50 \%$ and 40 for strain from $50 \%$ to $70 \%$. Various activities were successfully detected in real-time, such as swallowing, closing/opening of the mouth, and multi-angle bending of elbow, which illustrates the proposed sensor's potential as a wearable device for the human body.
\end{abstract}

Keywords: patterned strain sensor; mechanical property; repeatability; flexible electronics; human motion detection

\section{Introduction}

Wearable strain sensors attached to the human body have been explored recently as key components for potential applications in human motion detection and personal healthcare devices [1-3]. Flexibility, stretchability, good sensitivity, and conductivity are the essential characteristics of such smart wearable electronics to respond to the varied strains caused by human activities [4-7]. Great progress has been made in fabricating wearable strain sensors using metallic and carbon nanomaterials on flexible polymer to achieve these properties [8-12]. However, under external load conditions, cracks on the metallic surface and difficulty in repeatability are the key issues that restrict the application of wearable strain sensors $[13,14]$.

Among various wearable strain sensors, nano-metal films were frequently applied as the sensitive component in the sensor due to their excellent electrical conductivity and ductility [15]. However, external stresses can easily lead to the initiation of cracking in the surface of metal films, which results in a loss of durability, stability, and sensitivity for the device $[16,17]$. To solve the problem of circuit breaking caused by metal cracks, metal nanowires spin-coated on the polymer substrates were used instead of a deposited metal film $[18,19]$. The metal nanowires could be connected together as elastic conductive bridges to maintain conductivity because of the high length-diameter ratio. Still, the metal nanowire film could fail under large strain conditions due to the disconnection of the metal wires [20]. Another method was proposed in which metal films were deposited on the wrinkled substrates via pre-stretching, solvent treatment, and heat induction, which could successfully reduce the cracks on the 
metal surface under large deformation conditions [21-24]. However, the materials of nanowires and wrinkled patterns are irregular and difficult to be reproduced, resulting in the need for the performance detection and calibration of each device before use, thereby illustrating that these materials are unsuitable as wearable strain sensors. More importantly, because of the instability and randomness of the strain sensor in these investigations, no repeated experiment has been reported, which has made it difficult to apply the devices prepared in the research to industrial production. The objectives of this research are to enhance the mechanical stability and repeatability of a wearable strain sensor based on a regular patterned composite material.

In this paper, a wearable strain sensor with regular periodic surface patterns is fabricated with the aim of improving the stability and repeatability of the sensor through nanoimprint lithography (NIL). The mechanical stability was investigated by measuring the surface resistance change $\left(\Delta R / R_{0}\right)$ for initial state and cyclic loads. These experiments were explored on multiple repetitive tests to investigate repeatability. Then, the patterned wearable strain sensor was evaluated via attaching it to a human body to detect various activities.

\section{Experimental Section}

\subsection{Materials and Characterization}

Polydimethylesiloxane (PDMS) precursor and PDMS curing agent were purchased from Dow Corning SYLGARD (Midland, MI, USA). The purity of the silver target used for deposition was 99.99\%. The $\mathrm{SiO}_{2}$ mold $\left(25 \times 25 \mathrm{~mm}^{2}\right)$ had a periodic line array patterned with pitch of $200 \mathrm{~nm}$, line width of $100 \mathrm{~nm}$, and depth of $200 \mathrm{~nm}$. Although it is more conducive to improving the mechanical stability of patterned devices with a small period and large aspect ratio, the imprinting and demolding process with a high aspect ratio and small period is a major issue in nanoimprinting technology [25-27]. The period of $200 \mathrm{~nm}$ and aspect ratio of 2:1 are relatively mature parameters in nanoimprint technology, being more conducive to the successful preparation of patterns.

A vacuum drying oven (Lange, IPC-25, Baoding, China) was employed to cure the PDMS polymer. The metal layer was deposited by vacuum thermal evaporation (Vnano, VZZ-300, Beijing, China). Scanning electron microscopy (SEM; Hitachi, S-4800, Tokyo, Japan) images were obtained to study the morphology features of the films. The resistances of the strain sensor were measured using a multimeter (UNI-T, UT890C+, Dongguan, China).

\subsection{Device Fabrication}

Figure 1 shows a schematic diagram of the fabrication of the patterned metal/polymer device for a wearable strain sensor through NIL. The elastic layer PDMS (weight ratio of 10:1) was spin-coated on the patterned mold, and then the PDMS was cured under a pressure of 25 bar at $70{ }^{\circ} \mathrm{C}$ for $4 \mathrm{~h}$ in the vacuum drying oven [28]. After being peeled off the mold, Ag thin film (100 nm thickness) was deposited on the patterned PDMS substrate. A specific deposition condition (deposition current $=170 \mathrm{~A}$ ) and cooling condition (PDMS substrate was fixed on the cooling plate) were employed to fabricate the specimens. Then, two copper wires were connected to the Ag film using an electrode (silver paste), and the other ends of the copper wires were connected to the multimeter. Both ends of the specimen were the loading regions. Finally, a PDMS film was spin-coated and cured on the surface of the patterned film to prevent the Ag layer from being oxidized, leading to interface failure. The size of the fabricated sensor is shown in Figure 1. The center of Figure 1 shows the picture of the patterned PDMS/Ag/PDMS strain sensor specimen. 


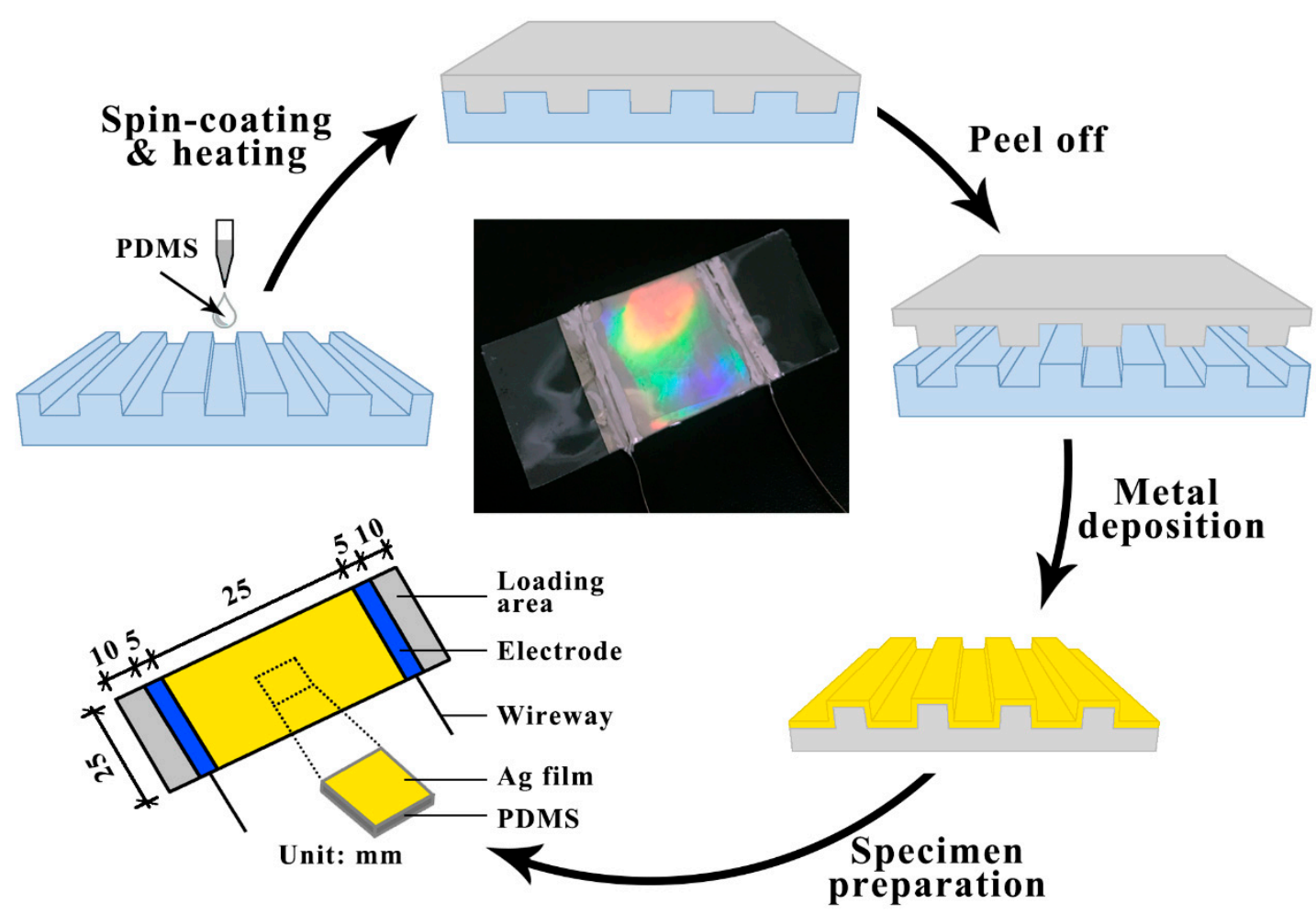

Figure 1. Schematic diagram of the fabrication process of the patterned strain sensor specimen.

\section{Results and Discussion}

\subsection{Morphology of the Patterned Strain Sensor}

Figure 2 shows the SEM images of the patterned strain sensor with nanoscale grating patterns. The top-view SEM image of the patterned strain sensor in Figure 2 clearly shows the grating structure with a period of $200 \mathrm{~nm}$. The sectional view shows that the mold is completely filled and the Ag film has a thickness of $100 \mathrm{~nm}$ on the horizontal surfaces. The Ag film on the side walls or corners of the patterned PDMS surfaces is weaker than the horizontal surfaces due to the vertical deposition of the Ag film during the vacuum thermal evaporation process. The results show that the mold patterns were perfectly transferred to the film surface through reversal imprint, and the Ag film covered the PDMS surface.

\subsection{Mechanical Stability}

\subsubsection{Tensile Property and Gauge Factor}

Figure 3a shows the setup used to measure the resistance for the sensor under different amounts of strain. The sensor was secured to a Vernier caliper by two insulating jigs. The appropriate strain was achieved by moving the Vernier caliper. The resistance was measured by the multimeter, which was connected to the alligator clip and the copper wires. Figure $3 b, c$ shows the measured $\Delta R / R_{0}$ of the patterned strain sensor under different amounts of strain to investigate the tensile properties. The values in Figure 3b,c are the averages of six samples, and the error lines are the maximum and minimum values from the six measured samples employed to explore the stability and repeatability. Figure $3 b$ shows the $\Delta R / R_{0}$ of the patterned strain sensor under the initial state. The initial average resistance $\left(R_{0}\right)$ of the strain sensor was $14.3 \Omega$, which is higher compared to the previous studies for bare Ag/PDMS composite material. This is because the Ag films on the side walls or corners of the patterned PDMS surfaces are weaker than the horizontal surfaces. In addition, the $\Delta R / R_{0}$ of the specimens increased with the strain. The Ag film on the patterned PDMS had a small $\Delta R / R_{0}$ and 
a small error range, indicating that the fabricated strain sensor has good stability and repeatability. This is more significant for cyclic loading.

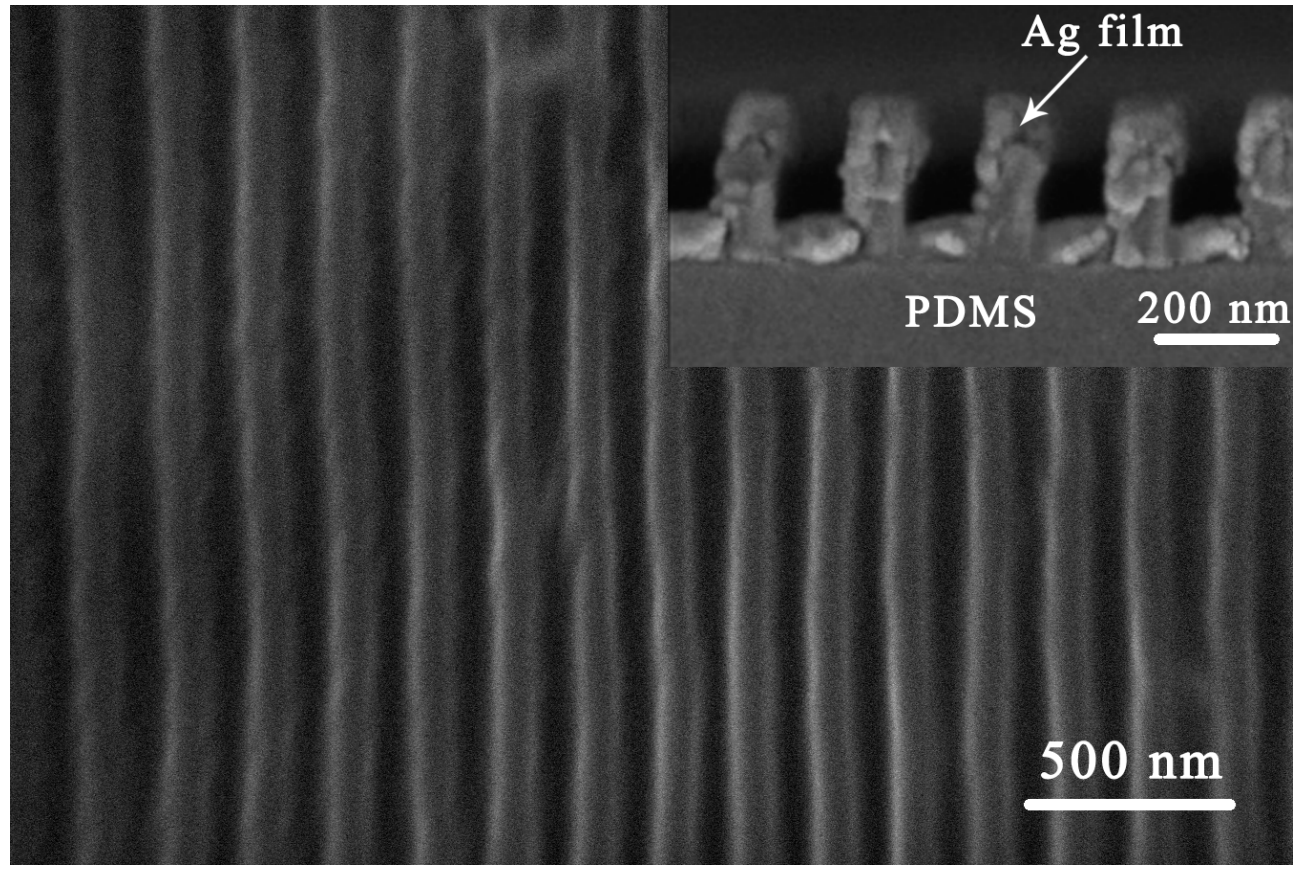

Figure 2. The SEM images of the patterned strain sensor.

(a)

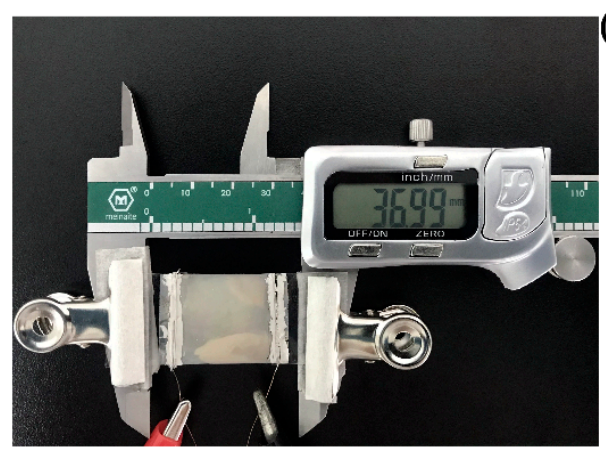

(c) 16

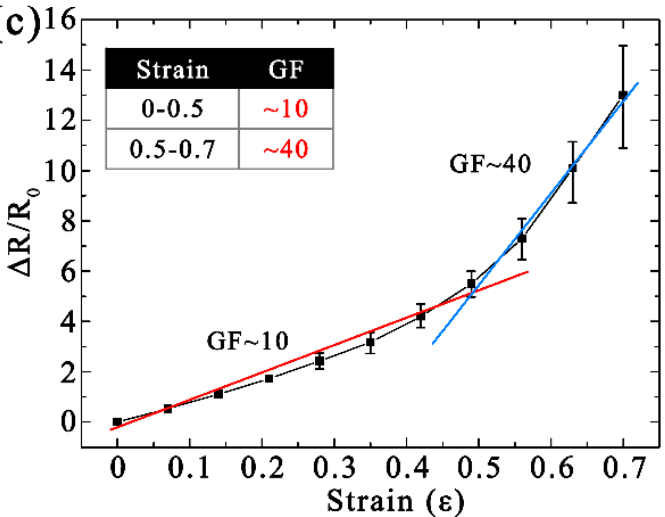

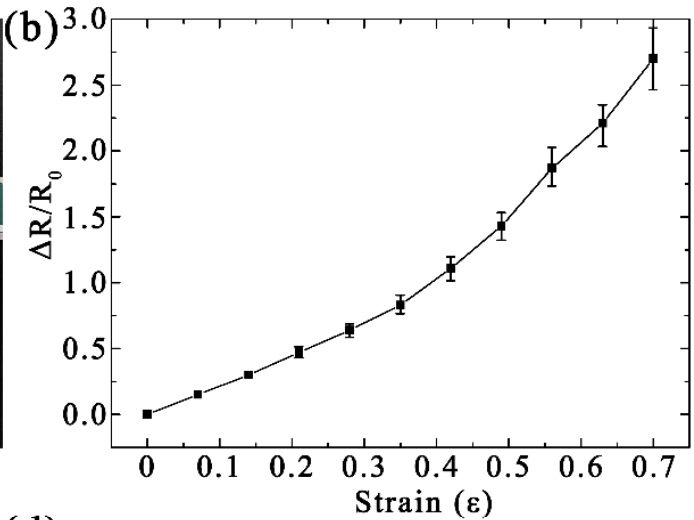

(d)

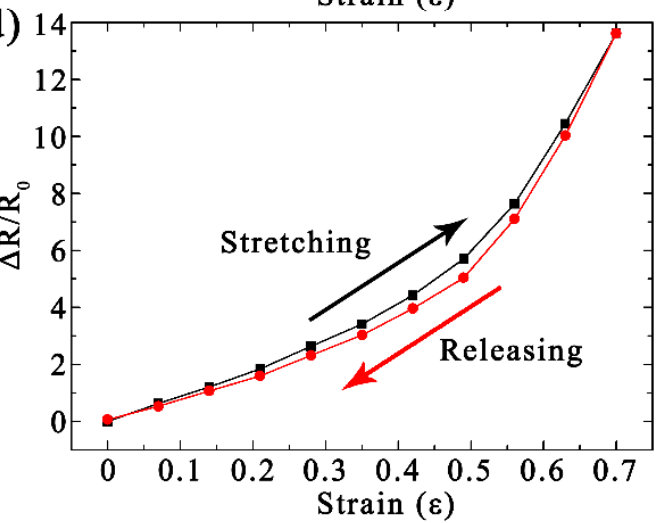

Figure 3. (a) Photograph of the experimental setup for measuring the resistance under different amounts of strain. The measured strain-dependent relative $\Delta R / R_{0}$ of the patterned strain sensor under (b) the initial state and (c) after cyclic loading. (d) Hysteresis curves under stretch/release cycles and 0.7 applied strain. 
Figure $3 c$ shows the $\Delta R / R_{0}$ of the patterned strain sensor after cyclic loading (1000 cycles with a strain of 0.5 ). The $R_{0}$ change rate of the strain sensor was approximately $72 \%$ (from 14.3 to $24.6 \Omega$ ) after cyclic loading. More importantly, when the strain was below 0.5 , the $\Delta R / R_{0}$ error lines of the strain sensor were very small, indicating that the patterned films have good stability under a cyclic tensile load for six repetitive tests. As the strain continued to increase, the $\Delta R / R_{0}$ error lines gradually expanded. With the stretching of the patterned sensor, this process can be divided into two stages: film expansion and crack propagation. When the strain increases, the patterned metal film will be spread with the stretched substrate, which is still a continuous metal surface. There are few cracks at this stage, so the error lines of this stage will be very small. As the strain continues to increase, the Ag film will produce small cracks in the weakened place.

The gauge factor $\left(\mathrm{GF}, \mathrm{GF}=\left(\Delta R / R_{0}\right) / \varepsilon\right)$, calculated by the slope of the colored curve in Figure 3c, can be used to evaluate the sensitivity of the strain sensor $[29,30]$. The strain of the sensor increased to $50 \%$, showing a moderate GF of $\sim 10$. The GF significantly increased to $\sim 40$ with the strain range from 0.5 to 0.7 . The increase in the GF of the sensor is attributed to the small cracks in the weak points caused by the large strain. The patterned strain sensor possessed not only a higher GF but also a higher sensing range, which is attributed to the periodic nanopatterns on the surface [5,31].

Figure $3 \mathrm{~d}$ shows the hysteresis curves under stretch/release cycles and 0.7 applied strain. The specimen used is patterned sensor after cyclic loading. When the strain was reduced from 0.7 to 0 , only a slight hysteresis was observed with the $\Delta R / R_{0}$ increased by $6.2 \%$ relative to the initial value owing to the cracks in the Ag film. These results indicate that the patterned strain sensor is highly reversible with minimal hysteresis during the process of stretching/releasing within a strain of $0-0.7[6,32]$.

\subsubsection{Bending Property}

Figure 4 shows the bending properties of the patterned strain sensor. Similar to the tensile test, the sensor was secured to a Vernier caliper by two insulating jigs, and the appropriate bending radius was achieved by moving the Vernier caliper. The average $R_{0}$ was $14.3 \Omega$, as mentioned above, under the initial state. As shown in Figure $4 \mathrm{a}$, the $\Delta R / R_{0}$ of the specimens increased with the bending radius. According to the error lines shown in Figure $4 \mathrm{a}$, the device maintained stable performance with a bend radius of less than $10 \mathrm{~mm}$. Figure $4 \mathrm{~b}$ shows the $\Delta R / R_{0}$ of the patterned strain sensor after cyclic loading (1000 cycles with a bending radius of $10 \mathrm{~mm}$ ). The average $R_{0}$ change rate of the strain sensor was approximately $22 \%$ (from 14.3 to $17.5 \Omega$ ) after cyclic loading. At this point, this strain sensor exhibited good bending resistance. It can be seen that from the error lines of Figure $4 \mathrm{~b}$ that the Ag film on the patterned PDMS substrate still had good stability when the bending radius reached $10 \mathrm{~mm}$. The good bending resistance and stability can be mainly attributed to the obviously improved mechanical occlusion effect induced by the contact properties of the patterned PDMS surface.

\subsection{Human Motion Monitoring}

In order to ensure the stability of the strain sensor, the specimen used for human motion monitoring was measured after cyclic stretching. The excellent sensitivity of the patterned sensor indicates that it can be applied to monitor small activities. Figure 5a shows the process of monitoring swallowing activities through the direct attachment of the sensor on the neck. The activities of the throat cause obvious movement when swallowing. As a result, the measured values of $\Delta R / R_{0}$ reached up to $27 \%$ for swallowing when the strain sensor was placed on the neck. In addition, when the strain sensor was attached to muscles around the mouth, and the observed $\Delta R / R_{0}$ was approximately $55 \%$ responding to the opening and closing process of the mouth, as shown in Figure $5 b$. 

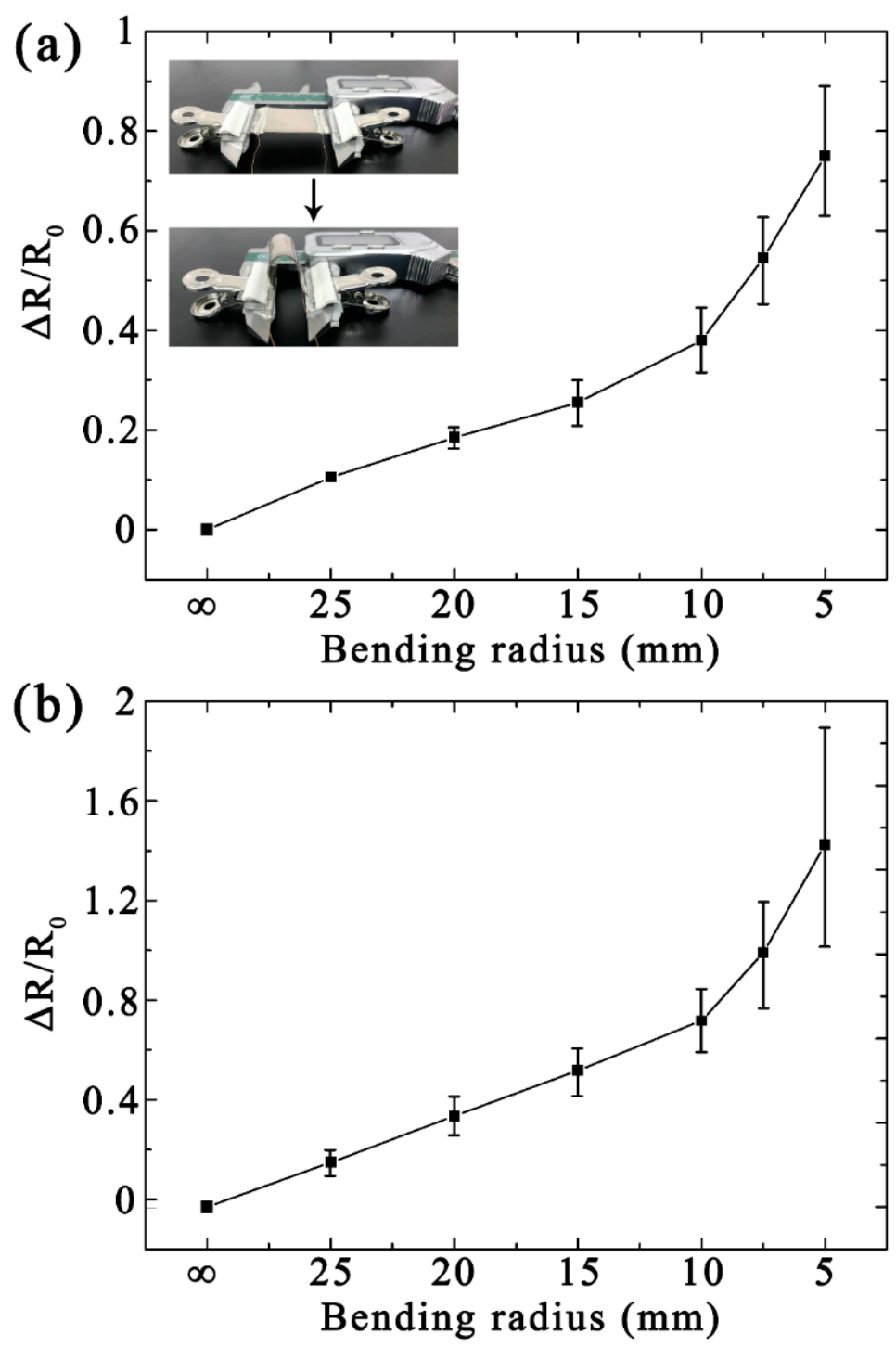

Figure 4. Measured bending-dependent relative $\Delta R / R_{0}$ of the patterned strain sensors under (a) the initial state and (b) after cyclic loading.

Based on its good sensitivity and stability, the patterned strain sensor can also be applied to detect human motions in large activities. Figure 6 shows the monitoring of elbow bending. To better demonstrate the performance of the fabricated sensor, as shown in Figure 6a, the strain sensor was employed to detect the multi-angle bending of the elbow, at $30^{\circ}, 45^{\circ}, 60^{\circ}, 75^{\circ}$, and $90^{\circ}$. As the bending angle of the arm increased, the strain sensor responses via a real-time signal showed increased values of $\Delta R / R_{0}$, as shown in Figure $6 \mathrm{~b}$. Moreover, for the frequently varied bending angles, the strain sensor showed excellent response and quick relaxation. 

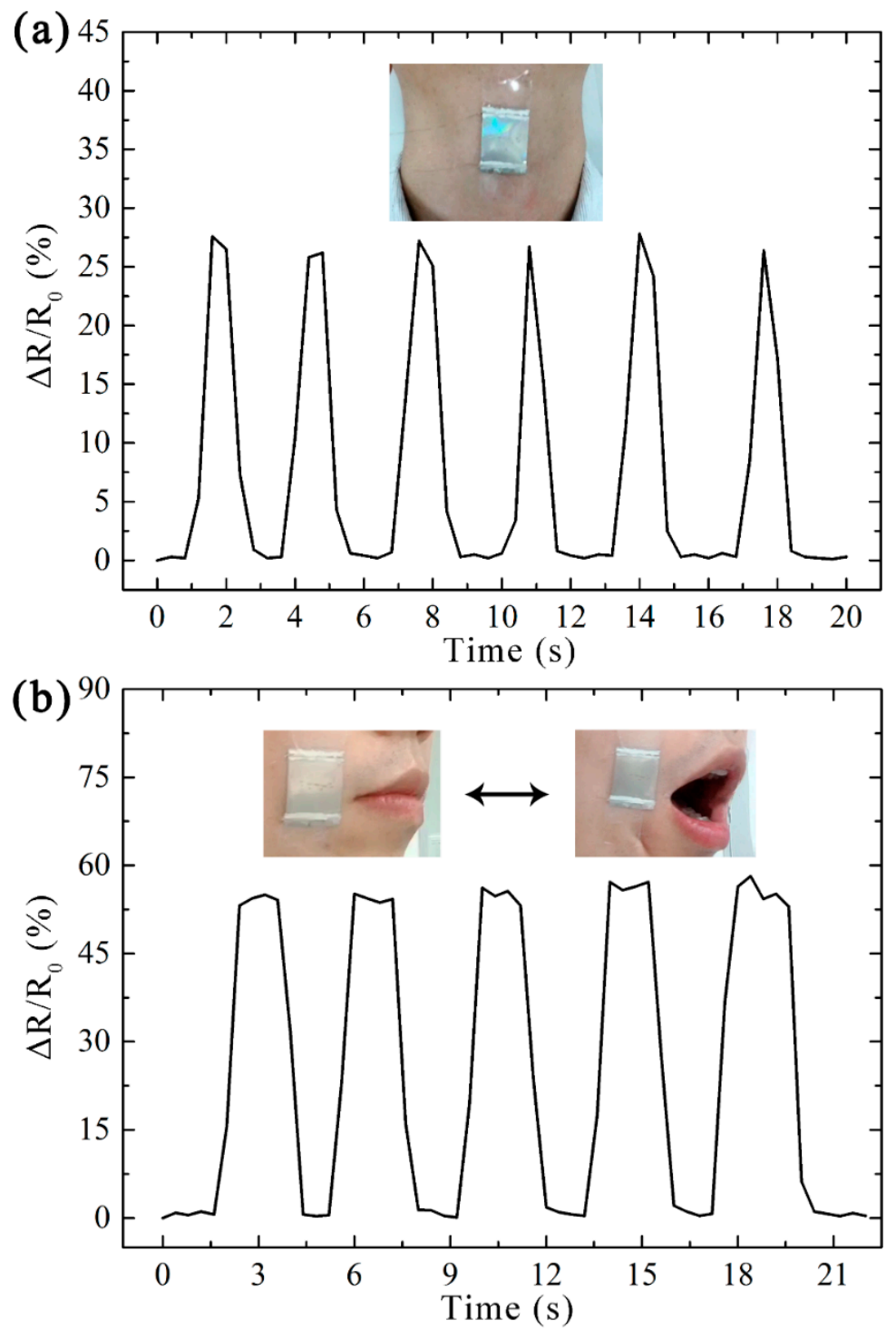

Figure 5. Photographs and real-time $\Delta R / R_{0}$ response of the strain sensor attached to (a) the neck and (b) the mouth to detect small activities.

As shown in Figures 5 and 6, the varied activities can be distinguished according to the peaks of the output signal. More importantly, due to the good reversibility of the sensor, the resistance can almost return to its initial value for each cycle during varied activities. Based on the intensity of the applied external load, the sensitive response proves the great abilities of our sensor for the detection and quantification of strain. These results illustrate that the proposed patterned strain sensor employed as a wearable device is capable of monitoring various activities of the human body in real time. 

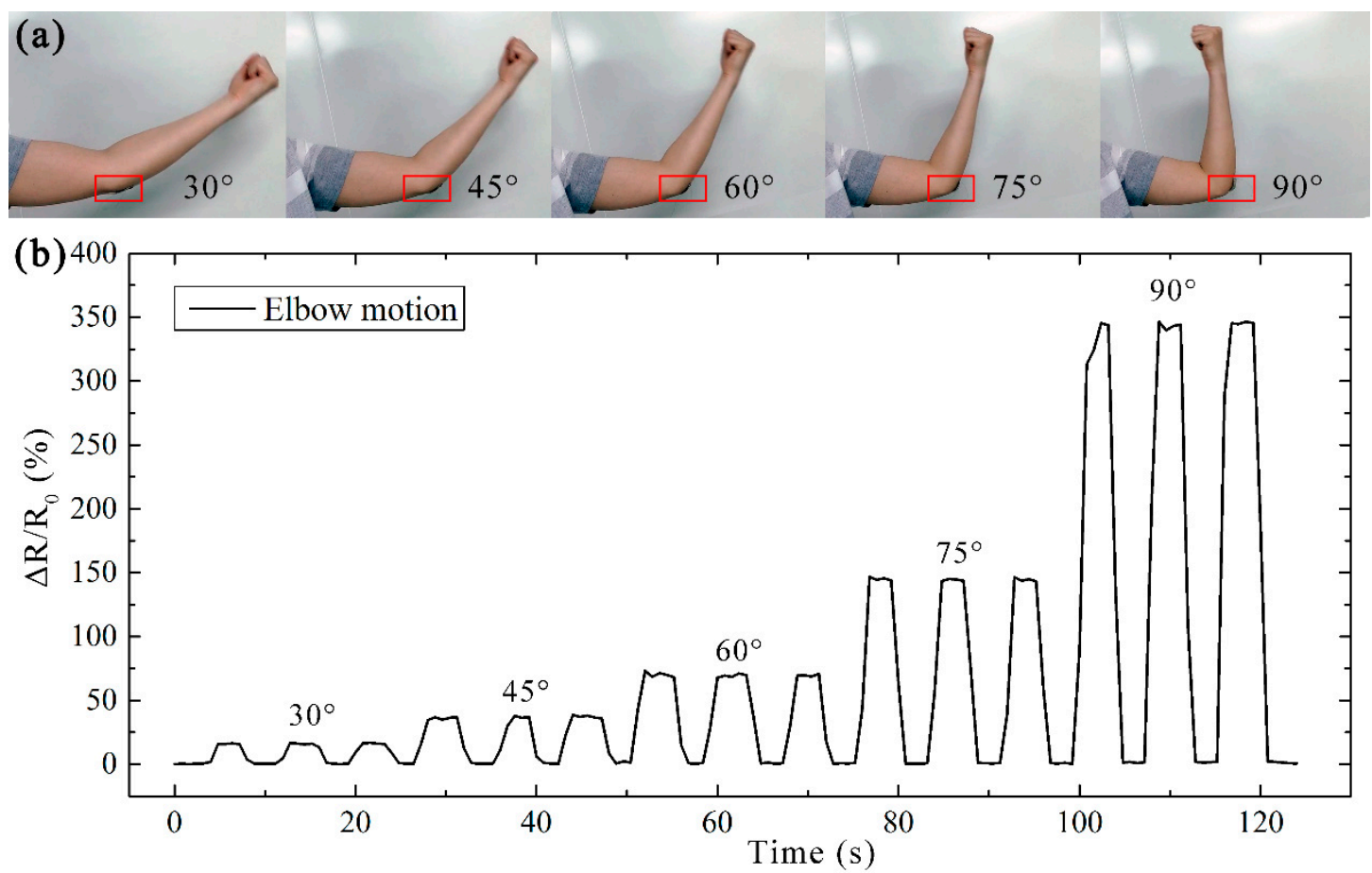

Figure 6. Elbow motion detection based on the patterned strain sensor. (a) Photographs of a real device under various bending angles, including $30^{\circ}, 45^{\circ}, 60^{\circ}, 75^{\circ}$, and $90^{\circ}$. (b) Real-time $\Delta R / R_{0}$ responses of the patterned strain sensor to cyclic motions of elbow bending.

\section{Conclusions}

A wearable strain sensor with high sensitivity and good repeatability based on a patterned Ag/PDMS composite material was successfully fabricated by NIL. The preparation method used in this paper resulted in a sensor that possesses good stability and repeatability under cyclic tensile or bending loading for repeated experiments. Moreover, the patterned strain sensor exhibited high sensitivity with GFs of 10 at a strain of less than $50 \%$ and 40 at a strain in the range of 50 to $70 \%$. Based on such desirable features, this sensor was successfully applied for the real-time detection of human motion activities from subtle activities to large joint motions. The varied activities could be clearly distinguished according to the peaks of the output signal. Moreover, owing to the excellent reversibility of the sensor, the resistance can almost return to its initial value for each cycle during the various activities. The good mechanical flexibility, stability, and repeatability of the patterned strain sensor illustrate its potential as a wearable device for the detection of various activities of the human body.

Author Contributions: Conceptualization, X.Z. and Q.W.; Methodology, X.Z. and J.L.; Formal analysis, X.Z., J.L. and Y.L.; Investigation, X.Z. and N.W.; Resources, Q.W.; Data curation, X.Z. and J.L.; Writing-original draft preparation, X.Z.; Writing-review and editing, Q.W. and X.Z.; Visualization, X.Z. and Y.L.; Supervision, Q.W.; Project administration, Q.W.

Funding: This work was supported by the Taishan Scholar Project of Shandong Province (No. TSHW20130956) and Natural Science Foundation of Shandong Province, China (No. ZR2017MA013).

Conflicts of Interest: The authors declare no competing financial interest.

\section{References}

1. Wang, X.; Liu, Z.; Zhang, T. Flexible Sensing Electronics for Wearable/Attachable Health Monitoring. Small 2017, 13, 1602790. [CrossRef] [PubMed]

2. Gong, S.; Cheng, W. One-Dimensional Nanomaterials for Soft Electronics. Adv. Electron. Mater. 2017, 3, 1600314. [CrossRef] 
3. Liu, Y.; Wang, H.; Zhao, W.; Zhang, M.; Qin, H.; Xie, Y. Flexible, Stretchable Sensors for Wearable Health Monitoring: Sensing Mechanisms, Materials, Fabrication Strategies and Features. Sensors 2018, 18, 645. [CrossRef] [PubMed]

4. Luan, J.; Wang, Q.; Zheng, X.; Li, Y.; Wang, N. Flexible Metal/Polymer Composite Films Embedded with Silver Nanowires as a Stretchable and Conductive Strain Sensor for Human Motion Monitoring. Micromachines 2019, 10, 372. [CrossRef] [PubMed]

5. Lu, L.; Wei, X.; Zhang, Y.; Zheng, G.; Dai, K.; Liu, C.; Shen, C. A flexible and self-formed sandwich structure strain sensor based on AgNW decorated electrospun fibrous mats with excellent sensing capability and good oxidation inhibition properties. J. Mater. Chem. C 2017, 5, 7035-7042. [CrossRef]

6. Li, X.; Hu, H.; Hua, T.; Xu, B.; Jiang, S. Wearable strain sensing textile based on one-dimensional stretchable and weavable yarn sensors. Nano Res. 2018, 11, 5799-5811. [CrossRef]

7. Park, H.; Kim, J.W.; Hong, S.Y.; Lee, G.; Kim, D.S.; Oh, J.h.; Jin, S.W.; Jeong, Y.R.; Oh, S.Y.; Yun, J.Y.; et al. Microporous Polypyrrole-Coated Graphene Foam for High-Performance Multifunctional Sensors and Flexible Supercapacitors. Adv. Funct. Mater. 2018, 28, 1707013. [CrossRef]

8. Makireddi, S.; Shivaprasad, S.; Kosuri, G.; Varghese, F.V.; Balasubramaniam, K. Electro-elastic and piezoresistive behavior of flexible MWCNT/PMMA nanocomposite films prepared by solvent casting method for structural health monitoring applications. Compos. Sci. Technol. 2015, 118, 101-107. [CrossRef]

9. Luo, S.; Obitayo, W.; Liu, T. SWCNT thin film enabled fiber sensors for life-long structural health monitoring of polymeric composites-From manufacturing to utilization to failure. Carbon 2014, 76, 321-329. [CrossRef]

10. Karim, N.; Afroj, S.; Tan, S.; He, P.; Fernando, A.; Carr, C.; Novoselov, K.S. Scalable Production of Graphene-Based Wearable E-Textiles. ACS Nano 2017, 11, 12266-12275. [CrossRef]

11. Wei, Y.; Chen, S.; Lin, Y.; Yuan, X.; Liu, L. Silver nanowires coated on cotton for flexible pressure sensors. J. Mater. Chem. C. 2016, 4, 935-943. [CrossRef]

12. Ho, M.D.; Ling, Y.; Yap, L.W.; Wang, Y.; Dong, D.; Zhao, Y.; Cheng, W. Percolating Network of Ultrathin Gold Nanowires and Silver Nanowires toward "Invisible" Wearable Sensors for Detecting Emotional Expression and Apexcardiogram. Adv. Funct. Mater. 2017, 27, 1700845. [CrossRef]

13. Lee, E.; Kim, T.; Suh, H.; Kim, M.; Pikhitsa, P.V.; Han, S.; Koh, J.S.; Kang, D. Effect of Metal Thickness on the Sensitivity of Crack-Based Sensors. Sensors 2018, 18, 2872. [CrossRef] [PubMed]

14. Lee, I.; Kim, S.; Yun, J.; Park, I.; Kim, T.S. Interfacial toughening of solution processed Ag nanoparticle thin films by organic residuals. Nanotechnology 2012, 23, 485704. [CrossRef] [PubMed]

15. Wang, C.; Zhao, J.; Ma, C.; Sun, J.; Tian, L.; Li, X.; Li, F.; Han, X.; Liu, C.; Shen, C.; et al. Detection of non-joint areas tiny strain and anti-interference voice recognition by micro-cracked metal thin film. Nano Energy 2017, 34, 578-585. [CrossRef]

16. Ibru, T.; Kalaitzidou, K.; Baldwin, J.K.; Antoniou, A. Stress-induced surface instabilities and defects in thin films sputter deposited on compliant substrates. Soft Matter 2017, 13, 4035-4046. [CrossRef] [PubMed]

17. Zhang, X.; Mu, Y.; Dodaran, M.; Shao, S.; Moldovan, D.; Meng, W.J. Mechanical failure of $\mathrm{CrN} / \mathrm{Cu} / \mathrm{CrN}$ interfacial regions under tensile loading. Acta Mater. 2018, 160,1-13. [CrossRef]

18. Sang, S.B.; Liu, L.H.; Jian, A.Q.; Duan, Q.Q.; Ji, J.L.; Zhang, Q.; Zhang, W.D. Highly Sensitive Wearable Strain Sensor Based on Silver Nanowires and Nanoparticles. Nanotechnology 2018, 29, 255202.

19. Cho, J.H.; Ha, S.H.; Kim, J.M. Transparent and stretchable strain sensors based on metal nanowire microgrids for human motion monitoring. Nanotechnology 2018, 29, 155501. [CrossRef]

20. Lee, C.J.; Park, K.H.; Han, C.J.; Oh, M.S.; You, B.; Kim, Y.; Kim, J. Crack-induced Ag nanowire networks for transparent, stretchable, and highly sensitive strain sensors. Sci. Rep. 2017, 7, 7959. [CrossRef]

21. Wen, Z.; Yang, Y.; Sun, N.; Li, G.; Liu, Y.; Chen, C.; Shi, J.; Xie, L.; Jiang, H.; Bao, D.; et al. A Wrinkled PEDOT: PSS Film Based Stretchable and Transparent Triboelectric Nanogenerator for Wearable Energy Harvesters and Active Motion Sensors. Adv. Funct. Mater. 2018, 28, 1803684. [CrossRef]

22. Lee, J.; Chung, S.; Song, H.; Kim, S.; Hong, Y. Lateral-crack-free, buckled, inkjet-printed silver electrodes on highly pre-stretched elastomeric substrates. J. Phys. D Appl. Phys. 2013, 46, 105305. [CrossRef]

23. Xin, Y.; Zhou, J.; Tao, R.; Xu, X.; Lubineau, G. Making a Bilateral Compression/Tension Sensor by Pre-Stretching Open-Crack Networks in Carbon Nanotube Papers. ACS Appl. Mater. Interfaces 2018, 10, 33507-33515. [CrossRef] [PubMed] 
24. Abu-Khalaf, J.M.; Al-Ghussain, L.; Al-Halhouli, A. Fabrication of Stretchable Circuits on Polydimethylsiloxane (PDMS) Pre-Stretched Substrates by Inkjet Printing Silver Nanoparticles. Materials 2018, 11, 2377. [CrossRef] [PubMed]

25. Zheng, X.; Wang, Q.; Zhang, R.; Ma, L.; Luan, J. Effects of aspect ratio and metal layer thickness on demoulding of metal/polymer bilayer gratings during nanoimprinting. Sci. Rep. 2018, 8, 12720. [CrossRef] [PubMed]

26. Sun, H.; Yin, M.; Wang, H. High Aspect Ratio Nanoimprint Mold-Cavity Filling and Stress Simulation Based on Finite-Element Analysis. Micromachines 2017, 8, 243. [CrossRef]

27. Ma, L.; Wang, Q.; Zhang, R.; Zheng, X.; Zheng, T. Effects of contact states on polymer pattern deformation during demolding process in nanoimprint lithography. J. Vac. Sci. Technol. B 2016, 34, 06K409. [CrossRef]

28. Zheng, X.; Wang, Q.; Luan, J.; Li, Y.; Wang, N.; Zhang, R. Angle-dependent structural colors in a nanoscale-grating photonic crystal fabricated by reverse nanoimprint technology. Beilstein J. Nanotechnol. 2019, 10, 1211-1216. [CrossRef]

29. Shaker, A.; Hassanin, A.H.; Shaalan, N.M.; Hassan, M.A.; El-Moneim, A.A. Micropatterned flexible strain gauge sensor based on wet electrospun polyurethane/PEDOT: PSS nanofibers. Smart Mater. Struct. 2019, 28, 075029. [CrossRef]

30. Biccai, S.; Boland, C.S.; O’Driscoll, D.P.; Harvey, A.; Gabbett, C.; O'Suilleabhain, D.R.; Griffin, A.J.; Li, Z.; Young, R.J.; Coleman, J.N. Negative Gauge Factor Piezoresistive Composites Based on Polymers Filled with $\mathrm{MoS}_{2}$ Nanosheets. ACS Nano 2019, 13, 6845-6855. [CrossRef]

31. Kim, J.; Park, S.J.; Nguyen, T.; Chu, M.; Pegan, J.D.; Khine, M. Highly stretchable wrinkled gold thin film wires. Appl. Phys. Lett. 2016, 108, 061901. [CrossRef] [PubMed]

32. Souri, H.; Bhattacharyya, D. Highly stretchable and wearable strain sensors using conductive wool Yarns with controllable sensitivity. Sens. Actuator A Phys. 2019, 285, 142-148. [CrossRef]

(C) 2019 by the authors. Licensee MDPI, Basel, Switzerland. This article is an open access article distributed under the terms and conditions of the Creative Commons Attribution (CC BY) license (http://creativecommons.org/licenses/by/4.0/). 